\title{
PATRIMONIO ETNOLÓGICO Y JUEGO DE IDENTIDADES
}

\author{
JUAN AGUDO TORRICO
}

Universidad de Sevilla

\section{Resumen.}

En origen, el actual concepto de patrimonio surge de la intencionalidad política de reflejar una imagen de identidad unívoca, acorde con los estados-naciones que irán surgiendo en el transcurso del s. XIX y XX. Sin embargo, hoy en día el patrimonio ha de dar respuesta a nuevas imágenes identitarias, originadas tanto por la fragmentación de identidades que caracteriza nuestra sociedad, como a su valor de consumo como recurso económico.

\section{Palabras clave:}

Patrimonio cultural, patrimonio etnológico, identidades, tradición.

\section{Abstract.}

In principle, the nowadays concept of heritage arise from the political purpose of reflecting an univocal image, according to the rising of the nation-states during the course of the 19th and 20th centuries. However, at present the heritage have to provide answers to new identity images, developed because of the fragmentation of the identities that characterize our society, and his consumer good as economic resource.

\section{Keywords:}

Cultural heritage, ethnological heritage, identity, tradition. 


\section{EL PATRIMONIO NO EXISTE, SE INVENTA}

En el presente el concepto de patrimonio cultural, al menos en el mundo occidental, forma parte de una amplia conciencia colectiva, manifiesta en el frecuente uso del término patrimonio (como sustantivo o adverbio) con una diversa gama de significados: ya sea para referirnos a los viejos monumentos definitivamente admirados como bienes culturales consolidados o, crecientemente, para reclamar que una valoración patrimonial similar se aplique a los más diversos elementos o aspectos (prácticas culturales, conocimientos) de nuestro entorno. E incluso, lo más significativo, para cuestionar el uso privativo o la falta de interés de la administración por otros referentes culturales que hoy estimamos forman parte de nuestros modos de ser (tradiciones), o son manifestaciones culturales que "debieran" ser protegidos o al menos reseñados por su significación identitaria o por ser testimonios de la capacidad creativa de diferentes colectivos.

Sin embargo no es extraño que también nos encontremos con intentos de limitar tanto el uso como la aplicación de este concepto de patrimonio, aunque ahora no provendrá tanto de los sectores "populares" que históricamente habían quedado excluidos de la producción y/o disfrute de estos bienes patrimoniales (monumentos, antigüedades y obras de arte de antaño), como de los sectores sociales dominantes que sí estuvieron en el pasado relacionados con estos hitos de creaciones singulares que han ido jalonando los tiempos. Las nuevas miradas sobre el patrimonio dejan paso a unos discursos más abiertos y no siempre concordantes con aquellos otros relacionados con el poder y una imagen circunscrita a unos valores y modelos políticos unívocos y uniformizadores.

En la relación contrastiva entre lo que nos queda del pasado, ya sea como testimonios pretéritos o manifestaciones en uso (arquitectura, modos de vida, gastronomía, rituales, etc.), y las imágenes de modernidad del presente, no siempre salen ganando estas últimas, como así se creía inequívocamente hasta bien entrado el siglo XX. Aunque para determinadas prácticas socio-profesionales y modelos económicos desarrollistas, incluso potenciados desde instituciones públicas, se sigue cuestionando abiertamente este concepto de patrimonio/conservación frente a la idea de modernidad/cambio: véase al efecto los conflictos urbanísticos en las poblaciones con destacados conjuntos 
históricos ${ }^{1}$; de la frecuente crítica a los parques naturales y la limitación de usos que los pongan en peligro, etc.

En estos casos no deja tampoco de ser sorprendente que se mantengan, para cuestionar los discursos patrimonialistas a los que se enfrentan, la escasa innovación en los "discursos de modernidad" en los que se apoyan: la protección de estos entornos o bienes patrimoniales conlleva un "antinatural" inmovilismo, opuesto al desarrollo "natural" de la historia y urbanismo; responden a conceptos e imágenes retrógradas, provincianas, "catetas", etc. Y, por supuesto, obstaculizan cuando no van abiertamente en contra del desarrollo económico (al menos "dan trabajo" mientras se destruye el paisaje o los viejos edificios que hay y se construye aquello que va a sustituirlo), y, en última instancia, se suele añadir como argumento que quien sabe si con estas actitudes conservacionistas no se está obstaculizando la creación de un patrimonio para el futuro. Afirmación esta última que no deja de ser un argumento capcioso dado que no se emplea para defender tanto un potencial patrimonio del futuro como para evitar la reticencia frente a la destrucción de lo que hay y, sobre todo, imponer imágenes que quiebran los modelos consolidados y aceptados colectivamente como bienes a conservar.

Por otra parte, también hay quienes piensan que aunque el concepto de patrimonio cultural tal y como hoy lo conocemos no fuera desarrollado hasta bien entrado el s. $\mathrm{XX}^{3}$, los bienes que lo integran tienen un valor inmanente que los hace ser apreciados de por sí como bienes patrimoniales incuestionados. Como mucho se trataría de "descubrir", de difundir o poner en valor en terminología patrimonialista, estos significados.

1. Nada más significativo de ello que lo que está ocurriendo en el momento de escribir este artículo con la construcción de la torre Pelli en Sevilla, un "edificio de autor" de 180 metros de altura promovido por una entidad bancaria y consentido, e incluso auspiciado, por el Ayuntamiento de la ciudad como ejemplo de "modernidad" y emblematismo. Para reforzar este hecho se ha construido en el límite permitido del Conjunto Histórico, lo que contribuye a destacar visualmente su contraste con los otros edificios históricos de la ciudad. Pese a la fuerte resistencia de múltiples colectivos ciudadanos y la amenaza de poner en riesgo por su impacto visual la declaración de la Unesco como Patrimonio de la Humanidad los edificios centrales de su Conjunto Histórico (Alcázar, Catedral y Archivo de Indias), ha podido más la demagogia de la modernidad y el poder económico-político de las instituciones implicadas que la protesta y contestación pública. Otro tanto podríamos decir respecto a la creciente interpretación que se hace en las revistas y "artículos sobre viajes" sobre el contraste entre los conjuntos históricos, patrimonializados, de las ciudades y las "nuevas arquitecturas de diseño": ahora los "repetitivos" son los sempiternos barrios antiguos con sus consabidos palacios, catedrales o murallas; mientras que la originalidad que se incita a conocer son estos edificios de autor, de por sí siempre originales, nada repetitivos y, por supuesto, verdaderos emblemas de las ciudades que tienen la suerte de contar con ellos.

2. Este último es el término empleado concretamente por el arquitecto que "firma" la torre a la que nos referimos en la nota anterior, para referirse al movimiento ciudadano opuesto a su construcción. Opinión y palabra, precisamente, nada original ni moderna.

3. Proceso en el que fue determinante la teoría de los Bienes Culturales desarrollada a partir de los años cincuenta, al tiempo que se abandonaban las viejas terminologías y clasificaciones de los "tesoros nacionales históricos-artísticos" para dar paso a los discursos patrimonialistas más poliédricos, abiertos e integradores que actualmente caracterizan la imagen y contenidos de este patrimonio cultural. 
Sin embargo, la realidad es muy otra. Como han puesto de manifiesto desde un principiolos autores que han ido desarrollando con el transcurso del tiempo la que hoy denominamos teoría patrimonialista (Rielgs, 1903; Choay, 1992; Prats, 1997), el patrimonio, los bienes culturales no existen como tales hasta que no se construye el discurso pertinente que crea, o reseña, y da a conocer los valores con los que se asocian, que deben justificar la estima colectiva en favor de dichos testimonios y, en consecuencia, defender su necesaria preservación.

El resultado es un complejo proceso que en cierto sentido particulariza a cada bien/ testimonio en sí mismo, en cuanto a los significados que justifican su valoración y preservación. La teoría de los bienes culturales se fundamenta en una serie de principios que bien podríamos considerar axiomáticos:

a) Ningún referente cultural tiene por sí mismo un valor inmanentemente patrimonial. Buen ejemplo de ello es lo que actualmente ocurre con "monumentos" o testimonios en los que concurren valores "arquitectónicos", "artísticos", o de cualquier otra categoría, pero que por su vinculación a personajes o hechos históricos del pasado reciente, son abiertamente cuestionables por los valores antidemocráticos y dictatoriales con los que se asocian, impidiendo que de hecho puedan entrar en la categoría de bienes patrimoniales, con la consiguiente polémica sobre qué hacer con ellos. Véase el significativo ejemplo del Valle de los Caídos franquista y de otros símbolos creados por la dictadura: edificios, esculturas situadas en lugares públicos, etc. Y otro tanto podemos decir del cambiante significado que se ha dado en el transcurso del tiempo a determinados personajes históricos o estilos artísticos, algunos de ellos largamente denostados (románico, barroco) y hoy ensalzados.

b) Cualquier elemento cultural de nuestro entorno es susceptible de ser patrimonializado: construcciones, sonidos y silencios, acontecimientos o personajes históricos, mitos o leyendas, paisajes, olores y sabores, etc.

c) La construcción de estos discursos es siempre selectiva, priorizándose según que contextos unos valores sobre otros, en razón del carácter polisémico que podemos aplicar a la inmensa mayoría de los bienes patrimonializados. Serían muchos los ejemplos a poner. Para el caso de Andalucía me gustaría reseñar uno en particular: el ejemplo de las grandes haciendas y cortijos (también podríamos hacerlo con palacios y conventos). En los discursos imperantes son reseñados como pervivencias de unos paisajes culturales y modos de habitar que se remontarían a las villas romanas y alquerías musulmanas, al tiempo que testimonian una peculiar arquitectura tradicional (popular) y recuerdan antiguos sistemas de aprovechamientos agroganaderos (lagares, almazaras, cuadras y tinaones, etc.). Pero poco o nada se nos dice de su simbología como manifestación de la estructura latifundista del agro andaluz y de las duras condiciones de vida de los jornaleros que vivieron y mantuvieron estos caserías. De hecho, al igual que ocurre con 
las construcciones palaciegas y los espacios "funcionales" destinados en estas grandes construcciones a la servidumbre, su "puesta en valor" rara vez dedica (ni aún en las descripciones planimétricas) un recuerdo a estos jornaleros, gañanes, boyeros, caseros, etc. que trabajaron en ellos.

d) En relación con lo anterior, estos valores y discursos son construcciones históricas, y como tales estarán en permanente revisión con el transcurso del tiempo. Tal vez sea esta una de las cuestiones más interesantes y significativas en los nuevos discursos patrimonialistas. En la medida en que un referente es o se quiere patrimonializar, se concentra sobre él una atención social, política y simbólica que nos obliga a tener muy en cuenta, y en su caso revisar, los valores colectivos que nos transmite o las razones socio-históricas por las que surgió. Es el caso, entre otros, de la revisión que hoy se hace de fiestas tan arraigadas como las de moros y cristianos, asociadas a valores simbólicos que rememoran cuestionables hechos bélico-religiosos e incluso etnocidas del pasado; si bien actualmente estos festejos ya no son vividos como expresión de unos principios dogmáticos religiosos que se revitalizan cada año, sino como actos festivos en sí mismos: su valor es la propia reproducción de la tradición, y el modo jocoso en que interactúan "moros" y "cristianos" poco tiene que ver con la "seriedad" que se quería dar a estas representaciones no hace demasiado tiempo. Pero aún así no deja de cuestionarse sus significados originarios llegando a ser motivo de conflicto, como ocurre cada año con la controvertida conmemoración festivo-ritual de la Toma de Granada. Y otro tanto podríamos decir de los festejos en los que intervienen o se vertebran en torno a animales y el trato que reciben (toros ensogados o embolados, suelta de vaquillas) cuando no se plantea abiertamente su desaparición: "fiesta nacional" de las corridas de toros. De hecho, la inclusión de estas fiestas en los catálogos de fiestas tradicionales reconocidas institucionalmente pretenden amparar su continuidad aun contraviniendo otras normas autonómicas en favor del trato que han de recibir los animales. E irónicamente, en el caso de las corridas de toros, la propuesta lanzada por algunas comunidades autónomas de declararlas Bienes de Interés Cultural (la máxima figura de protección patrimonial y de ámbito estatal) no es sino el intento de ampararlas bajo este mismo manto patrimonial para garantizar su continuidad; al contrario que en otras comunidades (País Vasco, Cataluña, Canarias) donde se han prohibido bajo el criterio contrapuesto de no proteger (y por lo tanto excluir de los discursos patrimoniales) aquellas prácticas culturales, por muy "tradicionales" que fueran, en las que se maltrate a los animales.

e) Al igual que serán valores cambiantes según el territorio. Los referentes que pueden ser exaltados en una colectividad como testimonios patrimoniales emblemáticos, pueden ser completamente ignorados o considerados secundarios en otras, incluso colindantes. Son muchos los ejemplos que podríamos poner, como es el caso de los chozos, arquitectura tradicional en desuso vinculada al mundo pastoril, considerados un 
testimonio emblemático de la cultura extremeña, contando incluso con una propuesta del parlamento de la Comunidad Autónoma de Extremadura para su protección; y sin embargo son ignorados por completo en la vecina comunidad de Andalucía, pese a compartir en grandes áreas (Sierra Morena) las mismas tipologías y significados socioeconómicos que en Extremadura. Otro tanto podríamos decir de los molinos de viento, inseparables de la imagen de Castilla la Mancha e ignorados en Andalucía, pese a contar con numerosos testimonios en las comarcas del Andévalo onubense, la Janda gaditana o el Cabo de Gata almeriense.

f) Por último, tal vez la aportación más destacable de esta teoría de los bienes culturales (que cuestiona precisamente a su predecesora que podríamos llamar de los "tesoros nacionales") es que los referentes seleccionados, y significados simbólicos con los que se asocian, no tienen porqué mostrar una imagen unívoca y homogénea de las colectividades que los adoptan como tales bienes patrimoniales, antes bien, deben reflejar su diversidad interna: territorios, género, grupos sociales, culturas del trabajo, etc.

En consecuencia, si el patrimonio responde a un discurso creado, ¿qué es?, ¿para qué se crea?. En nuestra opinión el patrimonio no es sino un concepto/valor aplicado a un determinado referente cultural, seleccionado para mostrar un imagen sincrética de un "nosotros" específico. Lo que convierte a dicho referente en un bien patrimonial es su capacidad de evocación, su conversión en un icono que rememora un tiempo pasado (bienes arqueológicos, históricos); la imagen y significación de un personaje real o mítico, o de un acontecimiento histórico; o unas prácticas o modos de vida en uso (rituales, oficios, paisajes) vinculados a unas tradiciones vivas.

Significativamente el concepto/valor de "patrimonio" marca una clara diferencia con el de "historia" en sí, e incluso con el de modos de vida activos. Sin entrar ahora en lo que es y no es historia (Pizza, 2000), sí es necesario reseñar que en los procesos de patrimonialización también realizamos una selección de nuestra historia: no todo el pasado se reactiva sino sólo aquella parte del mismo que estimamos ha aportado un valor meritorio (o al menos no negativo) en la construcción de nuestras "identidades". De no ser así, sólo son hechos del pasado que hay que tener en cuenta como parte de una historia que no podemos obviar porque ha ocurrido. Un ejemplo de ello podemos verlo en la difícil patrimonialización de los recuerdos vinculados con una institución tan omnipresente y de larga duración en la historia de España como fue la Inquisición: nos quedan numerosos testimonios de su existencia (toponimia, edificios relacionados con sus tenebrosas actividades) que podemos incluso museolizar o referir como anecdotario en otros circuitos culturales, pero es muy improbable que se llegue a recrear su existencia y prácticas, o que personajes relacionados con ella o símbolos que la rememoren lleguen 
a ocupar la centralidad de nuestras plazas o nomenclátor de nuestras calles ${ }^{4}$. Por el contrario, en la medida que la concepción y contenidos del patrimonio cultural ha ido mutando hacia el reconocimiento de unos símbolos y modos de vida más cercanos a cada comunidad concreta, en Andalucía las esculturas de nuestras plazas y denominación de las calles ya no hacen referencia a las imágenes homogeneizadoras de antaño, siempre relacionadas con personajes y eventos patrios incuestionables, sino que son ocupadas por personajes u otras simbologías relacionadas con un patrimonio cultural más próximo y reconocible: esculturas de artesanos o personajes relacionados con determinadas actividades locales predominantes (aceituneros, mineros, embarriladoras, etc.), memorias colectivas de fuerte rememoración (emigrantes), personajes simbólicos relacionados con sus sistemas rituales identitarios (danzantes, figuras de semana santa, personajes que identifican rituales específicos etc. ), o bien por personajes históricos que destacaron en alguna faceta sociocultural (cantaores, toreros, etc.).

Otro tanto podríamos decir de aquellos modos de vida fundamentados en costumbres, prácticas y actividades cotidianas. No todos ellos se integran en este patrimonio cultural, ni los consideramos representativos y/o significativos como para aplicarles el valor de tradiciones a conservar. En definitiva, el patrimonio no es historia ni modos de vida por sí mismos. Se crea a partir de la selección que hacemos de este pasado y presente, lo que nos lleva a la segunda pregunta que nos hiciéramos acerca del para qué se crea.

Dos son los factores que a nuestro juicio determinaron este proceso, con las implicaciones de los condicionantes del discurso a los que nos venimos refiriendo. El primero, que los valores transmitidos por este patrimonio han de ser considerados positivos, valiosos, capaces de generar una imagen evocadora que justifiquen, a partir de su potencialidad simbólica, la necesidad de su puesta en valor y preservación; y, sobre todo, que motive el deseo de conocerlo y/o consumirlo y/o reproducirlo: monumentos que evocan personajes o tiempos históricos, rituales en los que nos recreamos como colectividad, gastronomía que se identifica con lugares, etc.

En segundo lugar, el patrimonio nos remite a unos valores colectivos, nunca individuales. Aunque estos valores (imágenes identitarias) sí se activan con frecuencia a partir de prácticas individualizadas que requieren conocimiento o habilidades no siempre

4. Un debate interesante. La historia (tiempo) sin más no puede ser excusa interesada para preservar símbolos aparentemente ya "desideologizados", como ha ocurrido sistemáticamente con la falsa controversia sobre la permanencia de unos símbolos franquistas que llevaban "mucho tiempo" en un determinado lugar, incluidas estatuas del dictador. Sin embargo, al contrario que en tiempos no muy lejanos, hoy por hoy su retirada de los espacios públicos no conlleva su destrucción: han perdido su valor simbólico de ocupar la preferencia de espacios (calles, plazas, fachadas) que han de reservarse para referentes que enaltezcan o rememoren valores colectivos aceptados como positivos, para quedar como testimonios "históricos" que sí pueden formar parte de museos de la historia. 
asequibles al común de la colectividad: el saber hacer de un artesano que reproduce un oficio y elabora objetos que se identifican con el lugar en el que se elaboran; la virtuosidad de un músico que genera sonidos que evocan a un colectivo, territorio, ritual, etc.

Establecidas estas premisas, nos quedaría por definir la imagen del nosotros que pretendemos reflejar a través de este patrimonio. Una imagen, o más bien imágenes, que en el desarrollo de la teoría patrimonialista reflejan meridianamente bien la mutación que se ha dado y se sigue produciendo en los contenidos, significados y abarcabilidad de los bienes culturales que conforman este patrimonio.

\section{IDENTIDAD E IDENTIDADES EN EL JUEGO PATRIMONIALISTA}

El patrimonio no existe si no es como justificante ("demostración") de la existencia de una determinada identidad cultural, colectiva. Sólo esta afirmación justifica que pese a no ser unos bienes necesarios o funcionales desde una perspectiva socioeconómica, la sociedad demanda que se limite la disponibilidad de uso de quienes detentan estos bienes patrimonializados (un edificio palaciego, una cuadro, unas ruinas arqueológicas) y, sobre todo, que consienta que se dediquen recursos económicos a su adquisición, mantenimiento, o puesta en valor, detrayéndolos de otras necesidades sociales (educación, sanidad, etc.).(Agudo, 2003)

$\mathrm{Al}$ menos en origen, en el transcurso del siglo XIX al XX, los "tesoros nacionales" que darían luego paso (en la segunda mitad del s. XX) a los bienes y patrimonio cultural, tuvieron un valor casi exclusivamente político, ideológico; aunque para justificar por qué se seleccionaban unos y no otros referentes se recurriera a categoría aparentemente "objetivas": como era el peso de la historia que convertía a las "antigüedades" de antaño en "testimonios" relevantes de este pasado; o singularidades atribuidas a sus calidades artísticas y/o vinculación con determinados personajes históricos (artistas, literatos, etc.).

En este proceso mucho ha tenido que ver el origen y afianzamiento de los modelos de estado-naciones en el transcurso del s. XIX. Las identidades colectivas ya no se adscriben automáticamente a la condición de súbditos de un determinado reino como ocurriera en el Antiguo Régimen. En la nueva sociedad burguesa, las naciones se fundamentan en ciudadanos/pueblos cuya "realidad objetiva" estaría demostrada por la existencia de unas culturas diferenciadas y diferenciadoras, que justifiquen los contenidos y límites de estas naciones/estados. Los restos arqueológicos demuestran la "antigüedad" del origen de estos pueblos, mientras que los monumentos y grandes obras que jalonan la historia pasada vendrían a demostrar tanto el proceso de construcción de las identidades que concluyen en el presente, como la capacidad creativa de estos pueblos. La valoración de estos selectos tesoros nacionales se mide sólo en pasado, poniendo especial énfasis a la hora de seleccionarlos en aquellos periodos que se consideran más brillantes, o 
por su relación con destacados personajes ensalzados por su condición de héroes o mitos fundacionales de estos pueblos-naciones. Por este tiempo, los referentes que hoy englobamos dentro del patrimonio etnológico, vinculados a las expresiones, modos de vida, y saber hacer de la vida cotidiana y colectivos subalternos ("populares"), o no tienen cabida dentro de estos tesoros nacionales o se quedan como mucho relegados al interés, minoritario y parcial, de los estudios de folclore. $Y$ en el peor de los casos únicamente se estiman por sus valores "pintorescos": es decir, por recrear unas imágenes pictóricas, esteticistas, que sólo se tendrán en cuenta como contraste, o cuando no existan, de los otros monumentos histórico-artísticos.

Como refuerzo de lo anterior, estos tesoros nacionales, salvo los arqueológicos, son seleccionados en su inmensa mayoría entre referentes vinculados a las instituciones y sectores dominantes (iglesia, nobleza, concejos) de las antiguas sociedades, y adscritos predominantemente a sus subsistemas ideológicos y sociopolíticos. Van a cumplir, en su conjunto, el fin primordial de reproducir el discurso lineal de la creación y demostración de la imagen homogénea, unitarista, de una misma historia y cultura compartida a lo largo de un mismo tiempo: los grandes estilos histórico-artísticos se extienden por todo el "territorio nacional" (país), a la vez que se busca en ellos matices respecto a los mismos estilos en otras naciones (estilo gótico-isabelino, mudéjar, herreriano o barroco español), lo que reflejaría la capacidad creativa y singularidad de nuestros propios pueblos. Y lo mismo se podría decir de los personajes históricos resaltados en estos contextos patrimonialistas (por su condición de artistas creadores o por su vinculación directa con los monumentos u obras seleccionadas), reseñados por su aportación a esta historia común compartida y creadora de un pueblo-nación diferenciado.

\section{MUTACIÓN DE SIGNIFICADOS Y CONTENIDOS}

En esta fase de la teoría patrimonialista que se extiende hasta bien entrado el s. XX predomina indudablemente un discurso político, ideológico, amparado en el predominio, no menos ideológico, que van a tener desde la segunda mitad del s. XIX disciplinas académicas como son la Historia y el Arte.

No quiero decir con ello que no existiera en este proceso ningún otro interés economicista, mercantilista, unido al reconocimiento y difusión de estos tesoros nacionales. Pero su potenciación como "recurso cultural" (económico) que motive, práctica por entonces inexistente, un turismo cultural masivo atraído por los mismos, es otra cosa. Como mucho, por entonces, se hablaba de selectos "viajeros" atraídos por determinados referentes monumentales, y que compartían su condición de élite con los detentadores y herederos de algunos de estos tesoros nacionales más emblemáticos.

En la segunda mitad del s. XX se produce una significativa transformación en los contenidos del denominado, a partir de entonces, patrimonio cultural. Aunque el factor 
identidad (valor simbólico) sigue siendo determinante en la selección y contenidos de los referentes patrimonializados, los "nosotros" que se expresarán a través de estas construcciones van a ser diferentes, más diversos.

Desde los años setenta del s. XX asistiremos a una progresiva mutación de los contenidos y significados de patrimonio cultural: no se invalida o cuestionan los viejos tesoros nacionales ahora recalificados como patrimonio histórico (aunque sí desaparece por su ambigüedad el adjetivo de artístico), al tiempo que se extiende esta valoración a otros testimonios o prácticas culturales, en un proceso inacabado, que se han dado en llamar "patrimonios emergentes".

La consideración de este nuevo patrimonio cultural como fuente de recursos económicos (y no sólo como patrimonio costoso a mantener por su valor simbólico) va a ir cobrando importancia en las últimas décadas del pasado siglo; hasta transformarse en un factor clave en las políticas culturales hoy imperantes.

Son múltiples las razones que han llevado a esta situación. Pero todas ellas tienen como punto de partida el fenómeno socioeconómico revolucionario en la historia de la humanidad (aunque aún todavía hoy se está lejos de que sea un derecho consolidado y generalizado) a partir de los años cincuenta-sesenta del s. XX, del derecho sociolaboral a un tiempo de descanso remunerado (fines de semana, vacaciones, jubilación) que ha propiciado, a su vez, un nuevo tiempo de ocio social. A lo que unir el incremento de recursos económicos de amplios sectores sociales que ha permitido la conversión de este tiempo de ocio en un atractivo mercado.

Este sería el punto de partida, unido a la progresiva mejora y abaratamiento de los medios de transporte que posibilita un rápido y cómodo desplazamiento a cualquier lugar y en cualquier momento. Aunque este proceso no estuvo desde su comienzo vinculado al desarrollo y demanda de este patrimonio como recurso social y económico. Antes bien, en un primer momento la idea de este turismo de masas estuvo vinculada a una imagen de desarrollismo y modernidad predatoria ${ }^{5}$ (¿ha desaparecido o se cuestiona del todo hoy en día?) en nada favorable a la puesta en valor y preservación de este patrimonio, o al menos de lo que actualmente estimamos como tal: destrucción de los núcleos urbanos de las poblaciones costeras, depredación del paisaje, etc.

Sólo posteriormente, en el transcursos de las últimas décadas del s. XX, y a la par que se cuestionan algunos de los valores de modernidad de las nuevas sociedades industrialesurbanas, se replanteará el valor de algunos de estos referentes culturales, hasta entonces

5. Pese a lo que nos muestran las imágenes oficialistas del momento, donde la selección de unos pocos referentes monumentales emblematizados encubrían la realidad de la destrucción urbanística, e incluso de la desvalorización de la propia cultura de origen en la que se insertaban estos testimonios culturales folclorizados (Hernández, 2008). 
ignorados o depredados. Aunque con frecuencia no será por su valor de uso (significados colectivos y aportación a la memoria y vida social del colectivo que los conserva), sino por su valor de consumo, de mercado.

Progresivamente, el hecho de aplicar a un determinado referente (da igual que sea un monumento, producto gastronómico o tradición culinaria) el valor de considerarlo referente simbólico (patrimonial) de un determinado lugar, acontecimiento, o tiempo histórico, lo hace atrayente como producto de consumo; lo particulariza frente a los anodinos usos y consumos cotidianos de nuestro mundo globalizado. De ahí su atractivo como bien de consumo, garantizando su originalidad (¿calidad? ¿autenticidad?) por este hecho patrimonializador. Pero hablar de patrimonio como recurso, de su potencial demanda por un "turismo cultural" en alza supone con mucha frecuencia una lectura contradictoria con su propia simbología cultural: no se trata de un patrimonio que debe ser preservado de por sí, por su capacidad de evocación simbólica y usos sociales con los que se relaciona, sino que, al contrario, la imagen de este patrimonio debe de adaptarse a la demanda creada y esperada desde los centros urbanos emisores de este turismo cultural, con el patrocinio de las instituciones públicas y empresariales que lo gestionan o promueven. Es lo ocurrido con las imágenes ruralizantes estandarizadas que vemos en todos lados: paredes de piedra y madera vista, arreos de labranza colgados de las paredes, museos locales con un contenido e incluso disposición de las piezas reiterativa. Pero también con los espacios escenificados y recorridos acotados que se promueven por los conjuntos históricos, con los monumentos que se seleccionan y priorizan en los folletos divulgativos; para hacer creer que en el tiempo corto disponible según los intereses de las empresa turística de turno se puede ver (consumir) todo lo que de interés hay en dicha población.

Por lo tanto, el "nosotros" que se pretende recrear a través de estos discursos patrimonializadores, y de expresar en los referentes seleccionados, ya no sólo responde a cuestiones de identidades políticas, sino también de mercado: el patrimonio, como venimos diciendo, también se consume.

\section{LOS OTROS “NOSOTROS”. PATRIMONIO ETNOLÓGICO Y EXPRESIÓN DE LA DIVERSIDAD INTERNA DE CADA COLECTIVIDAD}

No obstante, el excesivo énfasis que con frecuencia se pone en la consideración del patrimonio cultural como potencial "recurso económico" no invalida la justificación inicial que motivó el desarrollo de la teoría y práctica patrimonialista: su condición de reflejo y expresión de unas determinadas identidades colectivas.

Todo lo contrario, en este proceso que venimos denominando de mutación en sus contenidos y significados, se mantienen los viejos referentes que fueran patrimonializados como "tesoros nacionales", pero se le añaden nuevos significados (cuando no se revisan 
los preexistentes), al tiempo que se amplían los contenidos del patrimonio cultural, en un proceso que siempre permanecerá inacabado. Son los denominados patrimonios emergentes, en los que el patrimonio etnológico, sus contenidos y significados, ha desempeñado un papel crucial.

En la nueva concepción patrimonialista ${ }^{6}$, el principio axiomático de que los bienes seleccionados lo son porque "pertenecen a todos" en su condición de manifestaciones simbólicas de unos determinados procesos históricos o modos de expresión colectivos, se complementa ahora con la afirmación no menos axiomática de que en este patrimonio, los bienes seleccionados, también debemos estar "todos representados"; no sólo en un contexto simbólico, en principio inherente a todo referente patrimonial aunque se trate de un gran palacio o tumba imperial, sino en manifestaciones concretas que muestren la creatividad y diversidad interna de cada colectividad: museos etnológicos, arquitectura tradicional, oficios artesanos, paisajes culturales.

Ya no se trata de que sólo estén representadas las manifestaciones de un modo u otro vinculadas con las referidas instituciones y sectores sociales históricamente dominantes, con una selección de referentes mayoritariamente circunscritos a los subsistemas sociopolíticos e ideológicos; a partir de los años setenta del s.XX se impone definitivamente la necesidad y obligación de que este patrimonio refleje también la vida de los diversos grupos sociales que han conformado y conforman estas colectividades (cultura popular y tradicional), así como que sea reflejo del conjunto de los subsistemas socioculturales que articulan las culturales concretas: subsistema ideológico (creencias, prácticas religiosas, expresiones simbólicas), sociopolítico (modos de vida, prácticas cotidianas) e incluso el tecnoeconómico (oficios, actividades productivas).

Igualmente se producirá una quiebra significativa con respecto a otros dos discursos imperantes, de forma más o menos explícita, en las primeras lecturas patrimonialistas. El primero, al que se pone fin a partir de los años cincuenta del siglo pasado, va a ser la estrecha relación de aquellos primeros discursos entre patrimonio y "arte", y más en concreto, de la interpretación eurocéntrica que se ha hecho de esta siempre subjetiva percepción estética de objetos y monumentos (Méndez, 2009). Percepción de la que únicamente se salvaban algunas otras grandes civilizaciones que podían ser "comparables" en sus logros con las occidentales; aunque se pudiera discrepar sobre su adecuación o no a los "cánones" con los que se pretendía establecer criterios de objetividad en las interpretaciones de calidad estética fijados por esta última cultura occidental. Eran tiempos, años centrales

6. En este proceso la Unesco (1948) ha jugado un papel determinante, promoviéndolo y articulándolo, no sólo con unas formulaciones teóricas precisas y bien fundamentadas, sino también con el procedimiento de promover concretas Recomendaciones y, sobre todo, Convenciones que si bien no tienen valor jurídico preciso sí que obligan a los países que las suscriben a adaptar sus legislaciones nacionales a los principios en ellas recogidos. 
del s. XX, de la descolonización, con el consiguiente cuestionamiento de los valores culturales occidentales como únicos patrones, con lo que, igualmente, se ponía fin a las cosmovisiones universalistas que se empezaron a imponer en el s. XVI y se habían generalizado por la fuerza en los siglos XVIII y XIX. Al mismo tiempo, la quiebra de estos cánones nos sólo afecta a una más que cuestionable posible comparación jerárquica entre expresiones culturales similares (entre "civilizaciones"), sino que también cuestiona cuáles son las jerarquías de valor aplicables a los contenidos de cada cultura: si en alguna de las nuevas culturas reconocidas tras la descolonización faltan o son "poco relevantes" algunas de estas expresiones (arquitectura monumental, literatura escrita), aportan sin embargo otras extraordinarias expresiones culturales que en muchos casos se han perdido o son consideradas secundarias en el mundo occidental, como pueda ser la música tradicional, danzas, narraciones y literatura oral, preservación y respeto de los entornos naturales, etc. Se trataría, en definitiva, de manifestaciones culturales en uso, relacionadas con el crecientemente valorado "patrimonio inmaterial"7; una tipología patrimonial que, en cierta medida como efecto reflejo, comienza más tardíamente a ser valorada en el mundo occidental, rastreándose entre los otros "grandes patrimonios" lo que queda de este otro patrimonio inmaterial si no más "primitivo" (terminología hoy afortunadamente desarraiga), sí arcaizante y mantenido a través del tiempo por tradiciones que se han ido pasando de generación en generación.

Progresivamente, en cierta manera la quiebra de la imagen y discurso occidental jerarquizante respecto a otras culturas, también se produce a nivel interno dentro de estas mismas sociedades occidentales, con el cuestionamiento de los patrones impuestos desde la cultura del poder (predominantemente vinculada al mudo urbano), respecto a los demás sectores y territorios (mundo rural) subalternos dentro de las mismas colectividades.

7. Resulta interesante ver la eclosión de interés que se ha dado por esta "tipología patrimonial" inmaterial desde su reconocimiento por la Unesco en una convención específica (Convención para la salvaguarda del patrimonio cultural inmaterial. París, 2003) y la disparidad de aplicaciones: música, rituales, mitos, oficios y actividades. Irónicamente, para su puesta en valor se ha establecido, o al menos reseñado, una falsa dicotomía entre valores materiales e inmateriales: la propia concepción del hecho patrimonial se fundamenta en la inmaterialidad de los valores que lo motivan y evocaciones que se estimulan a través de nuestros sentidos, ya sean visuales, auditivos, olfativos, etc. Las ruinas de un castillo son patrimonializadas porque evocan a través de sus muros derruidos un tiempo histórico, personajes o acontecimientos; y lo mismo podemos decir de la participación en u observación de un ritual. En sentido contrario, el denominado patrimonio inmaterial es apreciado porque se materializa: en las notas que se transforman en sonidos, en la combinación de unos determinados ingredientes que dan como resultado una comida tradicional, en la diversidad de elementos que se combinan y activan para dar lugar a rituales específicos, etc. En realidad la única diferencia entre patrimonios/valores materiales e intangibles, estaría en el hecho de que en el primer caso son manifestaciones (materiales) permanentemente activas, mientras que los segundos sólo se activan y rememoran en determinados contextos que pueden ser cíclicos (rituales) u ocasionales (música, gastronomía). 
La segunda concepción imperante a cuestionar es la selección e interpretación de este patrimonio casi exclusivamente en clave de historia-pasado. Los "nuevos patrimonios" también se expresan en modos de vida o prácticas culturales que siguen vigentes, en uso; es decir, en lo que denominamos patrimonio etnológico.

De hecho, más que por su diversidad de contenidos, éste será el rasgo distintivo y diferenciador del patrimonio etnológico: su condición de un patrimonio vivo; que sigue siendo significativo para un determinado colectivo como para tratar de propiciar su continuidad. Aunque también ha sido y es una tipología patrimonial que se ha tratado de vincular y justificar como el resultante de las expresiones culturales de los colectivos subalternos de una determinada comunidad sociocultural; de ahí las peculiares denominaciones con las que se le ha conocido durante mucho tiempo: "patrimonio modesto", "patrimonio menor", "patrimonio subalterno"8. Lo cual, de ser cierto, paradójicamente nos llevaría a aplicar sus significados y contenidos como un valor transversal a la propia historia, y debiéramos de hablar de un patrimonio etnológico ibérico, romano o medieval, ateniéndonos a los periodos o épocas preestablecidos. Pero esto no ocurre así y todos los restos arqueológicos o artefactos que nos han llegado se incluyen sin más en vitrina o salas en las que ni siquiera se suelen clasificar por su funcionalidad original, sino por los periodos cronológicos o lugares con los que se relacionan. La materialidad y cronología se impone sobre otros valores culturales sobre los que apenas sí podemos hacer suposiciones: con frecuencia desconocemos cómo se les denominaba, quiénes los utilizaban, en qué contextos de usos funcionales o simbólicos podían modificar sus significados, etc. Y cuando nos han llegado algunos de estos "valores inmateriales", asociados o no a objetos, tiempos o espacios heredados del pasado, es más lo que suponemos o nos imaginamos de estas continuidades que lo que podemos afirmar "objetivamente" como tales, ya sea sobre los sonidos que denominamos "música celta", sobre perdidos cultos a la naturaleza que se dicen perviven en las fiestas y rituales de primavera como las cruces de mayo, etc.

Esta última cuestión nos lleva a otro de los ejes que consideramos definitorios de los contenidos y significados del patrimonio etnológico: no son los objetos, tiempos o manifestaciones concretas en las que se instrumentalizan los que dotan de valor a una determinada manifestación cultural, sino los valores sociales y simbólicos que se extraen (interpretan y usan) a través de los mismos.

Sorprende cuando analizamos los textos legislativos (y en ello la diversa interpretación

8. Hoy se le suele incluir en la categoría no menos curiosa de los "patrimonios especiales", supuestamente por requerir un tratamiento específico y diferenciado respecto a las grandes categorías de patrimonio mueble e inmueble. Así es citado en la nueva ley del Patrimonio Histórico de Andalucía (2007): "Los denominados Patrimonios especiales, según la terminología más extendida en la doctrina jurídica, [son ]...Patrimonios Arqueológico, Etnológico, Industrial, Documental y Bibliográfico." 
que podemos extraer de la abundante legislación autonómica en España constituye un laboratorio inigualable), e incluso programáticos sobre las diferentes tipologías patrimoniales, que no se detengan en analizar o describir cuáles son los fundamentos que definen y justifican al patrimonio arqueológico, qué concepción de la historia se aplica para el histórico, o de la estética-arte para el artístico; mientras que si lo harán en identificar cuáles son los fundamentos del patrimonio etnológico: cultura tradicional, identidad de los pueblos.

Aunque aún podemos encontrar algunas referencias, en extinción, a su condición de patrimonio relacionado con el siempre ambiguo concepto de cultura popular, en el discurso dominante predomina su vinculación con un modo de transmisión y permanencia amparado por la "tradición", y que caracteriza la identidad de los pueblos actuales.

Con la brevedad de análisis que exige un texto de estas características, sí quisiera reseñar que cuando hablamos de tradición desde una perspectiva antropológica lo hacemos teniendo en cuenta:

$1^{\circ}$.- Que los valores asociados con este concepto no son expresión de un tiempo acabado, que se transmite sin más a través de las generaciones. Todo lo contrario, las tradiciones para que subsistan han de estar permanentemente cambiando, adaptándose a los nuevos modelos sociales; de lo contrario serán "costumbres del pasado". En lenguaje común resulta difícil que se hable de "tradiciones del pasado" aunque sí de "costumbres de antes", la palabra tradición conlleva un significado de existencia en el pasado pero, sobre todo, de pervivencia en el presente.

Costumbres y tradiciones conviven en el mismo tiempo y es posible que intercambien sus significados, que algunas costumbres se conviertan en tradiciones o, en sentido contrario, que dejen de ser tradiciones para quedar como costumbres. Ambos valores y las prácticas en las que se materialicen, serán de uso y aceptación muy común, pero con el paso del tiempo sólo a las tradiciones les damos el derecho de transmitir unos valores colectivos que consideramos significativos y dignos de perpetuarse. Las tradiciones tienen también la función de generar un sentimiento si no de tiempo detenido sí de continuidad inalterada (estaban aquí cuando llegamos y lo seguirán estando cuando nos vayamos), en la que a la vez que nos insertamos en esta experiencia intergeneracional compartida, la vamos adaptando a los nuevos valores y cambios sociales, sin perder en este proceso la capacidad de evocación que nos hace creer que participamos de un acto atemporal, inalterable al paso del tiempo. Es el caso de unos rituales y festejos de los que han desaparecido los grupos sociales que les dieron origen y protagonizaron, o se han abierto a cambios impensables no hace demasiado tiempo, tal y como está ocurriendo con la antaño impensable participación de las mujeres, y aún menos de su protagonismo en contextos de los que antes estaban excluidas; lo mismo podríamos decir de oficios 
artesanos que incorporan nuevas tecnologías o producen objetos adaptados a las nuevas demandas. En definitiva, tanto el cambio como la permanente selección de qué referentes pretendemos etiquetar como tales son inherentes al concepto y puesta en práctica de las tradiciones.

2.- En segundo lugar, el concepto de tradición se nos presenta como "neutral" e interclasista. Frente al conflicto de definir el ámbito de pueblo/popular (¿colectividad étnica en su totalidad? ¿sectores sociales subalternos?) y la cuestionable pureza tanto de las expresiones relacionadas con las "culturas populares" como su antítesis de las "culturas dominantes" (Cirese, 1979; García Canclini, 1982). Ahora el eje vertebrador lo constituye el factor tiempo, pasado-presente (selección y continuidades), y modo de transmisión: intergeneracional, transmisión oral o por mímesis, saberes y prácticas adquiridas y transmitidas informalmente. Factores que condicionan el sentido que damos a la tradición como soporte de unos valores compartidos.

En consecuencia, las mismas prácticas y saberes son compartidos por muy diferentes sectores o clases sociales. De este modo ya no hay controversia en dónde termina lo culto y empieza lo popular, cuáles son las expresiones de las ideologías dominantes y las adaptaciones o reinterpretaciones que podemos escudriñar en las prácticas de los sectores sociales dependientes o subordinados (populares). Ello se pone de manifiesto en la mayor parte de nuestros rituales, pero también podemos apreciarlo en los contenidos de la denominada arquitectura popular donde con frecuencia se seleccionan ejemplos que poco o nada tienen que ver con los sectores sociales que ocupan la base de la pirámide social; y otro tanto podríamos decir de oficios artesanales donde lo único popular es la figura del artesano pero no de los productos que genera.

Así pues, en este contexto, las tradiciones, permanentemente recreadas y seleccionadas, con más o menos añadidos, nos remiten a unas comunidades simbólicas depositarias de conocimientos, saberes y prácticas culturales bien codificadas y adaptadas a los diferentes colectivos. En definitiva, de nuevo al concepto de identidades colectivas que dio origen al propio concepto de patrimonio.

Dicho así, el patrimonio etnológico se manifiesta y recrea en estas prácticas tradicionales, sin importar para el caso la rica diversidad de expresiones en la que se materializa: habla, oficios y actividades, rituales, música, danza, gastronomía, paisajes, arquitectura, mitos y leyendas.

De este modo, el tiempo del patrimonio ya no sólo se expresa en pasado, sino que también en presente; aunque este presente lo queramos relacionar con un pasado rememorado por una tradición que no deja de ser una memoria viva que activamos cíclica u ocasionalmente.

Pero hay otros factores, además de la interpretación de estos tiempos culturales, que van 
a resultar no menos claves en este complejo y a veces conflictivo proceso de mutación patrimonial, que con frecuencia centra la atención de los nuevos patrimonios en los valores asociados con el patrimonio etnológico: la eclosión de identidades, de reconocimientos de las mismas, que se produce en el transcurso de la mitad del s. XX. Nuevas identidades que al mismo tiempo que ponen en cuestión los modelos homogeneizadores primero impuestos por los discursos de los estados-nacionales y luego por las "lógicas" del mercado de la globalización, ha hecho que se reafirme cada vez más el deseo del reconocimiento de estas identidades, a la vez fragmentadas e integradas en muy diferentes contextos territoriales-sociales: desde lo étnico a lo local.

Significativamente, cuando tratamos de establecer o perfilar las siempre volátiles "señas de identidad" que identifican a estos colectivos, hoy en día van a estar vinculadas en su inmensa mayoría con este patrimonio etnológico: música tradicional, arquitectura tradicional, rituales y fiestas tradicionales, paisajes etnológicos, oficios artesanos, etc. Sin que con frecuencia importe mucho la ancestralidad de su origen o el en otros tiempos cuestionable valor primigenio de los mismos; solo importa su condición de tradicionales, ser sentidos y vividos como tales.

Sin embargo, decir que este patrimonio etnológico, que sólo puede ser entendido y valorado en el contexto integrador del patrimonio cultural como conjunto, no ha sido ni es en sí mismo ajeno al proceso de mutación de significados y contenidos a los que nos venimos refiriendo. Su reconocimiento tardío ${ }^{9}$ ha tenido que ver con el análisis que hemos hecho del proceso de "democratización" de los contenidos y significados del patrimonio, y de la fragmentación del reconocimiento de la diversidad de culturas que ha caracterizado y caracteriza la historia de la humanidad. Como hemos referido y brevemente analizado, en los valores que lo particularizan (tradición como concepto articulador, asociado a modos de vida en usos) su historia está por concluir.

No deja de ser llamativo que esta historia de reconocimiento y transformaciones comience

9. Si tomamos como referente la Recomendación de la Unesco de 1972 (Recomendación sobre la protección, en el ámbito nacional, del patrimonio cultural y natural) que se sigue considerando el principal documento programático en la formulación de los contenidos del patrimonio, va a ser a partir de este momento cuando se reconozca el patrimonio "antropológico", junto al "natural", en igualdad con el ya consolidado patrimonio histórico. 
por su propia denominación, si "patrimonio etnográfico" o "patrimonio etnológico"10 y que se está definitivamente decantando por esta última, tanto desde una perspectiva teórico/académica como de plasmación en los discursos institucionales de puesta en valor de los bienes patrimoniales relacionados con esta tipología.

Otro tanto podemos decir en este contexto de matización de significados, en cuanto al uso del término de "cultura popular"11 como soporte de este patrimonio etnológico, progresivamente desplazada si no propiamente por el de una "cultura tradicional"12 como sistema no menos difícil de perfilar que la primera, sí por el valor de la tradición como adjetivo aplicado a los múltiples contenidos del patrimonio etnológico, con el significado que habría que dar a este concepto de tradición según lo analizamos en las páginas anteriores. Y en este caso, como adjetivo/valor el término tradición sí aparece en las referencias o descripciones relacionas con el contenido del patrimonio etnográfico/ etnológico en todas las legislaciones patrimoniales del Estado español a las que nos venimos refiriendo.

Finalmente, resultaría difícil establecer una tipología precisa de los bienes a incluir en esta tipología patrimonial, dado que, como en todo tipo de patrimonio hablamos más de valoraciones que de tipologías formales. Y esto nos lleva a que podamos referir la existencia de bienes culturales con valor etnológico en cualquiera de los ámbitos de nuestro entorno cultural. Sólo dos legislaciones autonómicas se han atrevido a aventurar una propuesta, no cerrada, de elementos patrimoniales reseñados dentro de la categoría

10. Cuestión que no se ha de considerar meramente nominalista si nos atenemos al uso que se hace de dichos términos en la teoría antropológica. La mirada e interpretación etnográfica, dicho de forma breve, enfatizaría el valor del referente seleccionado (ritual, molino, danza) por lo que es en sí mismo, en lo que apreciamos; mientras que desde una perspectiva etnológica estos referentes cobran valor y se explican en su relación con el contexto, configuración cultural, del que forman parte: historia, agentes sociales que intervienen o con los que se relacionan, significación en el sistemas socioeconómico o festivo-ceremonial de la localidad. Y, sin embargo, pese a que desde la investigación e instituciones académicas relacionadas con la antropología fue siempre predominante el término etnológico (Prats e Iniesta, 1993), no siempre ha sido así en su aplicación institucional, muy probablemente por haberse citado como "patrimonio etnográfico" la primera vez que se establece esta tipología en la ley del Patrimonio Histórico Español de 1985. Hoy en día sigue primando el término patrimonio etnográfico en los museos de ámbito local, mientras que en las legislaciones autonómicas en 8 se define como etnográfico y en 9 como etnológico. En la andaluza de 1991 se definía como etnográfico, denominación que se cambia en la revisión del 2007 por el de patrimonio etnológico; y en la valenciana de 1998 esta tipología es clasificada como patrimonio inmaterial pero se definen sus contenidos como etnológicos.

11. Aunque solamente Cataluña tiene una ley específica dedicada al Fomento y protección de la cultura popular y tradicional (1993), la protección de esta cultura popular, expresada gramaticalmente en una fórmula que la une indiferenciadamente a la tradicional (“... cultura popular y tradicional”) nos la encontraremos en la legislación madrileña (1998), cántabra (1998), canaria (1999), extremeña (1999), asturiana (2001), castellano-leonesa (2002), navarra (2005) y en la murciana (2007). Por lo tanto, sin ser un concepto generalizado, sí está presente en un considerable número de estas legislaciones autonómicas.

12. Terminología que aparece explicitada en 14 de las 18 leyes existentes en España sobre patrimonio, incluida la estatal. 
de etnográfico/etnológicos, y en ambos casos no deja de sorprender su amplitud y diversidad: la ley canaria de 1999 y la riojana del 2004. En las demás, incluidas las dos anteriores, se habla de valores tradicionales, aplicados tanto a bienes muebles como inmuebles y, sobre todo, a saberes, modos de vida y actividades. Con lo que, desde estas mismas formulaciones base, y por todo lo que hemos referido, esta parte de nuestro patrimonio cultural ha estado vinculada, tiene su razón de ser, en uno de los valores que más se enaltecen como patrimonio emergente: el patrimonio inmaterial. Entendido éste tanto como valoración de las expresiones singulares en las que se materializa (rituales, oficios, música, ...) como, sobre todo, en el reconocimiento de los saberes y prácticas culturales que los reproducen y perpetúan como patrimonio vivo. No es de extrañar, por lo tanto, tomando nuevamente ejemplos paradigmáticos de nuestras legislaciones autonómicas, que de forma generalizada siempre haya estado asociado el patrimonio intangible al etnológico, vinculación que se hará claramente explicita en varias de ellas: en la ley vasca (1990: art. 53) se definen los "Bienes etnográficos inmateriales"; en la de Galicia (1995: art. 65) se habla de la "Protección de los bienes inmateriales" dentro del patrimonio etnográfico; en la de Baleares (1998: art. 67) se crea la tipología de "Bienes etnológicos inmateriales"; la de Aragón (1999: art. 75) define los "Bienes etnográficos inmateriales"; la extremeña (1999: art. 59), en referencia al patrimonio etnológico es la única que emplea el término intangible al definir la "protección de los bienes intangibles" ; y, por último, las valenciana (2004) y navarra (2005) harán una definición de bienes inmateriales más amplia, aunque priorizando igualmente su relación con la cultura tradicional. Se considera que el patrimonio etnológico será el que acoja aquellas manifestaciones más directamente vinculadas, en el imaginario colectivo pero también en las teorizaciones epistemológicas, con la cultura/patrimonio intangible: rituales, fiestas, lengua, tradiciones orales, oficios y actividades, música, canciones populares, además de costumbres, comportamientos, etc. Así lo expresa de forma bastante meridiana la Ley del Patrimonio Cultural Vasco cuando, en el artículo referenciado expresa que se habrán de salvaguardar "Los bienes etnográficos inmateriales, como usos, costumbres, creaciones, comportamientos, que trascienden de los restos materiales en que puedan manifestarse" o la de Galicia que indica en el mismo sentido que los bienes inmateriales "Tienen valor etnográfico y gozarán de protección aquellos conocimientos, actividades, prácticas, saberes y cualesquiera otras expresiones que procedan de modelos, técnicas, funciones y creencias propias de la vida tradicional gallega".

Nos quedaría por ver la vinculación del patrimonio etnológico con la nueva conceptualización del paisaje cultural: un concepto claramente transversal y presente en buena parte de las demás interpretaciones patrimonialistas, aunque la pugna por su apropiación se esté centrando en unas pocas disciplinas (geografía, urbanismo), obsesionadas incluso por una imposible objetivación y clasificación de los tipos de 
paisaje $^{13}$. De hecho si el paisaje no es sino la mirada interpretativa de un territorio fragmentado, en función de sus usos o simbologías, dentro de estas interpretaciones los términos de "lugar" $14 \mathrm{o}$ "paraje", nos vuelven a remitir a los vínculos de proximidad, de cotidianeidad, con los que asociamos los modos de vida que nos proporcionan los referentes que constituirán el patrimonio etnológico. Todo paisaje antrópico es un paisaje etnológico, reflejo del bien o mal hacer de la interacción del ser humano con sus entornos naturales. Su conversión en paisajes patrimonializados denota una apreciación valiosa de este interacción, y resulta difícil excluir de sus lecturas la mirada etnológica: sistemas de aprovechamiento (agroganaderos, silvopastoriles, mineros...), formas de hábitat (poblaciones, caseríos diseminados), usos simbólicos (santuarios), modificaciones del entorno (cercados de piedra, bancales, ...), etc.

En definitiva, las tipologías de bienes patrimoniales asociadas a los valores etnológicos no pueden desligarse del amplio concepto del patrimonio cultural, interactuando en muchos casos con otras miradas patrimoniales. Pero al mismo tiempo el patrimonio etnológico constituye una parte específica de este patrimonio cultural, teniendo por finalidad reconocer y poner en valor aquellas manifestaciones que dan lugar o son expresiones de unas prácticas sociales y modos de vida en uso dotadas de una significación relevante para una colectividad determinada. Podríamos decir que se centra en un patrimonio cotidiano, cercano, vinculado a unos modos de vida que fundamentan las identidades culturales del presente.

13. En el intento de matizar y ampliar el marco de referencia general establecido por la Unesco (1992) por el que los paisajes se encuadran en las tres amplias categorías de paisajes diseñados, paisajes evolutivos y paisajes culturales asociativos.

14. Frente a las imágenes aparentemente más rotundas de los "sitios", "zonas" o "conjuntos" que se suelen emplear para contextualizar los paisajes relacionadas con el patrimonio arqueológico, arquitectura monumental y centros urbanos, la imagen más cercana de lugar lo va a estar con el patrimonio etnológico, hasta llegar a configurar la figura específica de "Lugar de interés etnológico", creada por primera vez en la legislación andaluza sobre patrimonio histórico de 1985 y reproducida en las legislaciones autonómicas posteriores. 


\section{REFERENCIAS BIBLIOGRÁFICAS}

AGUDO TORRICO, Juan (2003) "Patrimonio y derechos colectivos". En V. Quintero y E. Hernández (coord.) Antropología y patrimonio: investigación, documentación e intervención. Granada: Junta de Andalucía, pp. 12-29.

(2005) "Patrimonio Etnológico: recreación de identidades y cuestiones de mercado". En Gema Carrera, Gunther Díetz (coords) Patrimonio inmaterial y gestión de la diversidad. Cádiz: Junta de Andalucía, pp. 197-213.

(2006) "Patrimonio cultural y discursos de identidad". En Kepa Fernández de Larrinoa (ed.) Intervención y vínculo. Reconstrucción social y peritaje antropológico en la administración pública e industria cultural del ocio. Pamplona: Universidad del País Vasco, pp. 61-85.

ALONSO IBAÑEZ, M. del Rosario (1992) El patrimonio histórico. Destino público y valor cultural. Madrid: Civitas.

CARRERA DÍAZ, Gema Gunther DIETZ (Coords) (2005) Patrimonio inmaterial y gestión de la diversidad. Cádiz: Junta de Andalucía.

CIRESE, Alberto M. (1979) Ensayo sobre las culturas subalternas. México: INAH.

CHOAY, François (1992) Alegoría del patrimonio. Barcelona. Gustavo Gili: 2007.

GARCIA CANCLINI, Nestor (1982) Las culturas populares en el capitalismo. La Habana: Casa de las Américas.

GONZÁlEZ ALCANTUD, J. Antonio (Ed.) (2003) Patrimonio y pluralidad. Nuevas direcciones en antropología patrimonial. Granada: Diputación Provincial de Granada. HERNÁNDEZ RAMÍREZ, Javier (2008) La imagen de Andalucía en el turismo. Sevilla: Centro de Estudios Andaluces.

LÓPEZ BRAVO, Carlos. (1999) El patrimonio cultural en el sistema de derechos fundamentales. Sevilla: Universidad de Sevilla.

MÁRMOL DEL, Camila, Joan FRIGOLÉ, Susana NAROTSKY (Eds). (2010) Los lindes del patrimonio. Consumo y valores del pasado. Barcelona: Icaria.

MÉNDEZ, Lourdes (2009) Antropología del campo artístico. Del arte primitivo al moderno. Madrid: Síntesis.

PAIS DE BRITO, Joaquim (2006) "Patrimónios e identidades. A difícil construção do presente". En Elsa Peralta e Marta Anico (Orgs.) Patrimónios e Identidades. Ficções Contemporâneas. Oeiras: Celta Editora, pp. 43- 51.

PENAS PUENTE, Roberto y Celia MARTÍNEZ ARMENTAL (Coords) (2008) O patrimonio etnográfico. A Coruña: Xunta de Galicia.

PERALTA, Elsa, Marta ANICO. (Orgs.) (2006) Patrimónios e identidades. Ficçoes contemporáneas. Oeiras: Celta Editorial.

PIZZA, Antonio. (2000) La construcción del pasado. Madrid: Celeste Ediciones.

PRATS i CANALS, Llorenç. (1997). Antropología y patrimonio. Barcelona: Ariel. 
PRATS i CANALS, Llorenç., Montserrat INIESTA I GONZALEZ (Coords), (1993) El patrimonio etnológico. Tenerife: FAAEE.

QUINTERO, M. Victoria, Elodia HERNÁNDEZ. (Coords.) (2003) Antropología y patrimonio: investigación, documentación e intervención. Granada: Junta de Andalucía.

RIELG, Alois. (1903). El culto moderno a los monumentos, su carácter y sus orígenes. Sevilla: Junta de Andalucía. 2007.

SIERRA RODRÍEGUEZ, X. Carlos, Xerardo PEREIRO PÉREZ. (Coords.) (2005) Patrimonio cultural: Politizaciones y mercantilizaciones. Sevilla: FAAEE. 